\title{
Residual Stress Simulation Based on the Effect of Element Diffusion on 316L/BNi-2 Brazed Joint
}

\author{
Baoan Wang ${ }^{\text {a }}$, Guoyan Zhou ${ }^{\text {b }}$, Dongxing Wang, Pengyang Duan \\ East China University of Science and Technology, Shanghai 200237, China \\ a1009582093@qq.com, bzhougy@ecust.edu.cn
}

Keywords: brazed joint, residual stress, diffusion, finite element method

\begin{abstract}
Residual stress is one of the important factors in the failure of brazed joints. In order to study accurately the residual stress in the brazed joints, the holding stage of brazing is taken into account. According to the microstructure of the brazed joint, a finite element model was built. The distribution of the residual stress of a $316 \mathrm{~L} / \mathrm{BNi}-2$ parallel brazed joint at $1075^{\circ} \mathrm{C}$ for $45 \mathrm{~min}$ was simulated. The results show that the diffusion stress of DAZ layer is compressive stress, and the maximum value is at the interface of BNi-2/DAZ. The compressive stress decreases gradually to zero along the boron diffusion direction. While both $\mathrm{BNi}-2$ layer and the $\mathrm{DAZ}$ layer are identified as residual tensile stresses, and the tensile stress in the $\mathrm{BNi}$-2 layer reaches the maximum value in the vicinity of joint corner.
\end{abstract}

\section{Introduction}

Due to the mismatch of the mechanical properties of the brazing material, the joint has a high residual stress in the brazing process, which is one of the important incentives for the joint failure ${ }^{[1]}$. However, Special after-welding stress treatment is not generally carried out, especially for stainless steel plate fin heat exchanger in the actual brazing process ${ }^{[2]}$. Therefore, in order to obtain a reliable brazing joint and extend the service life, the accurate prediction of the distribution and size of residual stress in brazed joints is particularly important.

Finite element method (FEM) to analyze the residual stress in brazed joints is an effective and feasible method. In recent years, Chen ${ }^{[3]}$ calculated brazing residual stress and thermal deformation of plate fin structure via FEM. In literature ${ }^{[4-6]}$ the residual stress in the plate fin structure is studied by FEM. The influence of process parameters on the residual stress was discussed. In addition, these previous works have made some assumptions: material is at a free state under the brazing temperature, and stress generation and its changes can only occur in the cooling process. In the actual vacuum brazing process, the melting element in the solder layer will diffuse into the matrix, react chemically with the matrix material and form an intermetallic compound region at the interface when temperature goes beyond the melting temperature of the solder, where the diffusion of atoms cause diffusion stress $\left[7^{-10}\right.$. Therefore, neglecting the diffusion process of the element and the microstructure change of the joint during the holding stage can lead to inaccurate calculation result.

In this paper, residual stress in the cooling process were calculated on the basis of the diffusion stress field generated during holding stage, and the stress and its distribution of the brazed joint were analyzed.

\section{Finite element analysis}

\section{Sample of brazing joint.}

The brazed joints in some plate fin structure can be regarded as parallel structural elements consisting of fins and plate, and the structural dimensions of one joint specimen are shown in Fig. 1. The brazing filler metal is $\mathrm{BNi}-2$ and the substrate is $316 \mathrm{~L}$. The holding temperature is $1075^{\circ} \mathrm{C}$ for 45 min. At the cooling stage, the assembly is cooled to the ambient temperature in the furnace. 


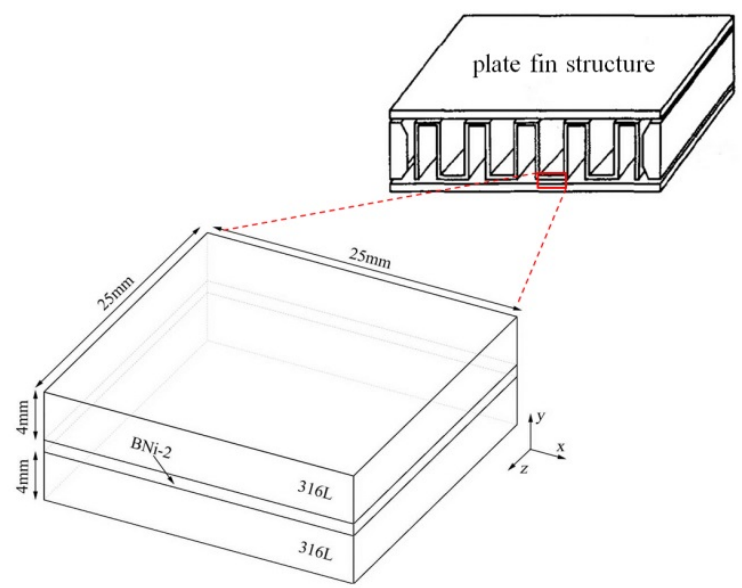

Fig. 1 The schematic of joint specimen

The specimen was observed by scanning electron microscopy after progressively polishing. As shown in Fig. 2 (a), it can be divided into isothermal solidified zone (ISZ), diffusion affected zone (DAZ), and matrix (BM). In this brazing process, the quality of the joint was satisfactory, for the BNi-2 layer did not show brittle phase (only the ISZ layer). DAZ layer width was about $52 \mu \mathrm{m}, \mathrm{BNi}-2$ layer thickness about $40 \mu \mathrm{m}$.
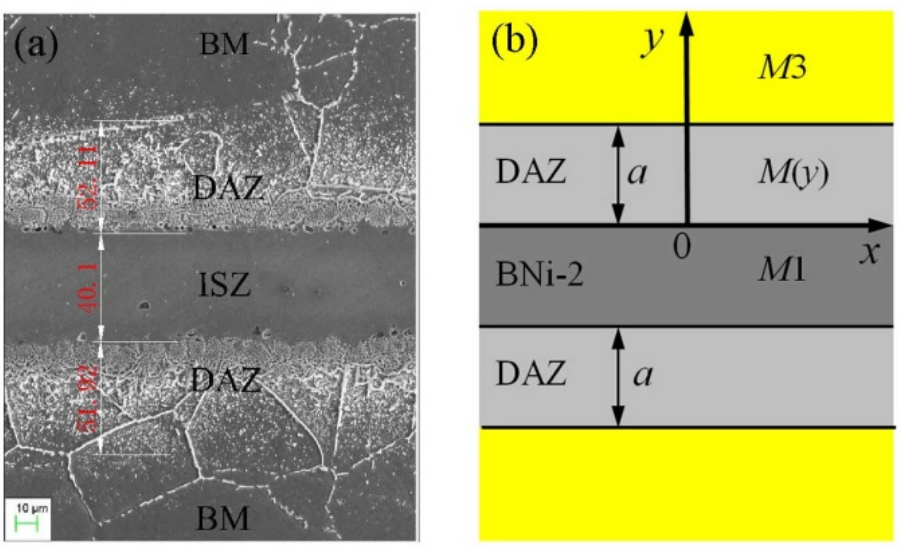

Fig. 2 Microstructure of joint: (a) Scanning electron micrographs; (b) Interface model

\section{Finite element model.}

From the microscopic analysis described above, there was a DAZ layer between the brazing filler metal and the metal substrate. Therefore, the role of the DAZ layer was taken into account in this study. Only one quarter of the parallel joint specimen was three-dimensionally modeled due to symmetry.

It can be seen from Fig. 2 (a) that DAZ layer can be divided into diffusion zone 1 (about 2/3) and diffusion zone 2 (about 1/3). Therefore, the whole DAZ layer was divided zone 1 and zone 2, as shown in Fig. 3. The element types of temperature and stress calculation are DC3D8 and C3D8R, respectively. There are totally 175000 elements and 184671 nodes in the 3D model.

Due to the symmetry of structure, two cross-sections of the 3D model are applied on the symmetric boundary conditions. And all the nodes on the bottom face are constrained in $y$-direction.

The DAZ layer is formed by the diffusion of boron elements of the brazing material into the matrix material, and the density of diffusion gradually decreases from the interface to the metal matrix, which is similar to functionally graded material. The elastic modulus and thermal expansion coefficient of the DAZ layer can be calculated by Eq. (1) ${ }^{[11]}$ :

$$
M(y)=M \exp (c \cdot y)
$$

Where $M(y)$ is DAZ layer material parameter, and $y$ is the coordinates of the DAZ layer along the thickness direction, as shown in Fig. 2 (b). $M 1$ is the material properties of BNi-2, M3 is the mechanical property of the matrix, and the $x$-axis is located at the interface of BNi-2/DAZ. Other properties of the DAZ layer are replaced by the base material. 
The material parameters of the brazing filler metal and the matrix are shown in Table $1^{[12-13]}$

\begin{tabular}{ccccccccc}
\hline Material & $\begin{array}{c}\text { Temp } \\
{ }^{\circ} \mathrm{C}\end{array}$ & $\begin{array}{c}\text { Specific } \\
\text { Heat } \\
\mathrm{kJ} /(\mathrm{kJ} \cdot \mathrm{K})\end{array}$ & $\begin{array}{c}\text { Density } \\
\mathrm{kg} / \mathrm{m}^{3}\end{array}$ & $\begin{array}{c}\text { Conductivity } \\
\mathrm{W} /(\mathrm{m} \cdot \mathrm{K})\end{array}$ & $\begin{array}{c}\text { Thermal } \\
\text { expansion } \\
10^{-6} /{ }^{\circ} \mathrm{C}\end{array}$ & $\begin{array}{c}\text { Young's } \\
\text { modulus } \\
\mathrm{GPa}\end{array}$ & $\begin{array}{c}\text { Possion } \\
\text { ratio }\end{array}$ & $\begin{array}{c}\text { Yield } \\
\text { stress } \\
\mathrm{MPa}\end{array}$ \\
\hline \multirow{6}{*}{ 316L } & 20 & 0.470 & 7966 & 13.31 & 15.24 & 195.1 & 0.267 & 278 \\
& 400 & 0.550 & 7814 & 16.33 & 17.44 & 172.6 & 0.322 & 154 \\
& 600 & 0.592 & 7724 & 22.38 & 18.21 & 155.0 & 0.296 & 141 \\
& 900 & 0.655 & 7583 & 26.33 & 19.11 & 116.8 & 0.24 & 86 \\
$\mathrm{BNi}-2$ & 6075 & 0.698 & 7486 & 28.67 & 19.66 & 81.1 & 0.223 & 22 \\
\hline & 60 & & & & 13.50 & 200.0 & 0.296 & 298 \\
& 600 & & & & 16.86 & 184.1 & 0.305 & 221 \\
& 0.458 & 7880 & 93.2 & 18.123 & 172.4 & 0.311 & 190 \\
& & & & & 21.41 & 127.4 & 0.35 & 124 \\
\hline
\end{tabular}

In this study, the stress field involves two processes: (1) the diffusion stress caused by the diffusion of boron in the holding stage; (2) the thermal performance changes caused by the mismatch of the material properties during the cooling stage. In the finite element simulation, the diffusion stress is taken as the initial state. Then the thermal stress analysis during the cooling stage is subsequently carried out. The sequential coupling method for thermal stress analysis is used.
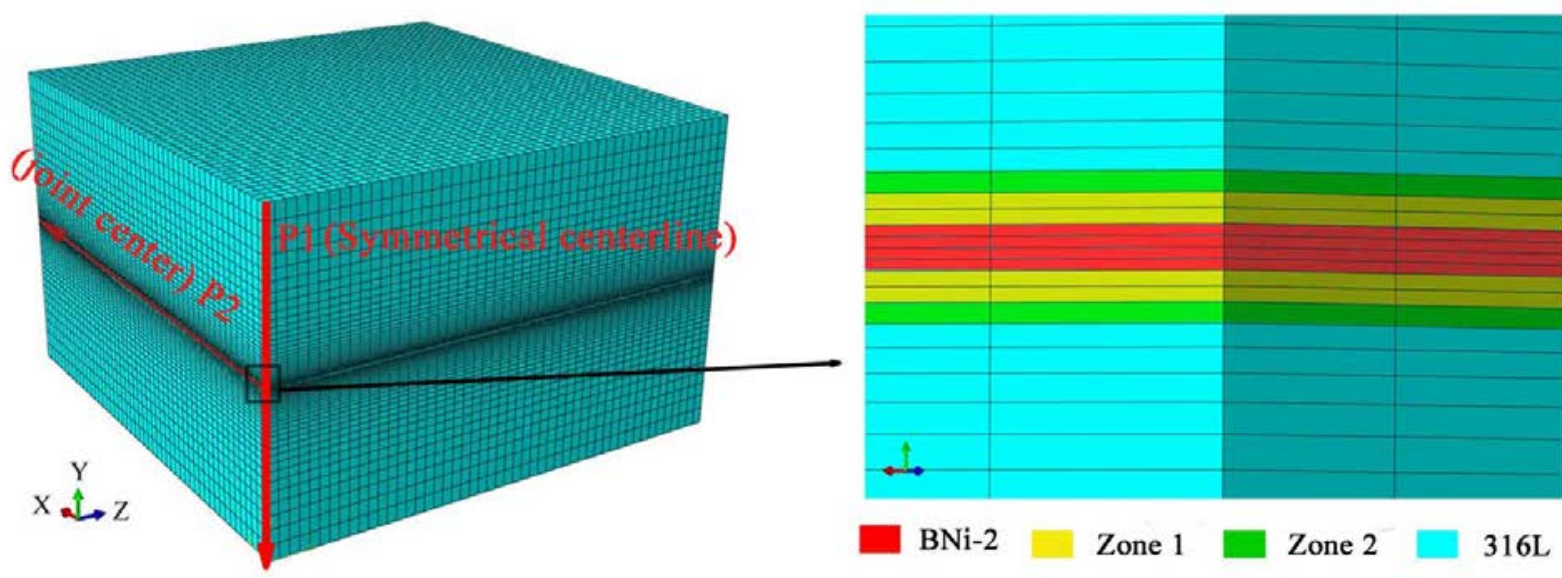

Fig. 3 Three-dimensional finite element model and mesh division of brazed joint specimen

\section{Calculation of initial diffusion stress.}

In interface model shown in Fig. 2 (b), it is assumed that the diffusion concentration of boron $C(y$, t) follow Fick's second law:

$$
\frac{\partial C}{\partial t}=D \frac{\partial^{2} C}{\partial y^{2}}
$$

At the initial time, the concentration of boron in DAZ is 0 , the boron concentration is $C_{0}$ at BNi-2/DAZ interface, and the concentration of boron is 0 at DAZ/BM interface. The microstructure of the DAZ region is Fe-rich boron (Fe-Cr-B), the solubility of boron is about $0.5 w t . \%{ }^{[14]}$. In other words, the concentration of the substance at the DAZ/BNi-2 interface is $3680 \mathrm{~mol} / \mathrm{m}^{3}$.

According to heat conduction differential equation:

$$
\frac{\partial T}{\partial t}=\frac{k_{i}}{\rho c} \frac{\partial^{2} T}{\partial x_{i}^{2}},(i=1,2,3)
$$

Where $k$ is the thermal conductivity, $\rho$ is the density, and $c$ is the specific heat capacity.

$$
D=\frac{k}{\rho c}
$$


From Eq. (4), it is related between Eq. (2) and (3), which can be converted into a concentration field into an equivalent temperature field.

Diffusion-induced strains can be characterized as Eq.(5):

$$
\varepsilon_{i j}=\frac{1+v}{E} \sigma_{i j}-\frac{v}{E} I_{1} \delta_{i j}+\frac{1}{3} C \Omega \delta_{i j},(i, j=1,2,3)
$$

Where $I_{1}$ is the first constant of the stress tensor, $C$ is the atomic concentration, $E$ and $v$ are Young's modulus and Poisson's ratio, respectively, and $\Omega$ is the partial molar volume.

Temperature-induced thermal strain can be characterized as Eq. (6)

$\varepsilon_{i j}=\frac{1+v}{E} \sigma_{i j}-\frac{v}{E} I_{1} \delta_{i j}+\alpha \mathrm{T} \delta_{i j},(i, j=1,2,3)$

Where $\alpha$ is the coefficient of thermal expansion (CTE).

$$
\alpha=\frac{1}{3} \Omega
$$

From Eq. (7), it is related between Eq. (5) and (6), which can be used to obtain the diffusion stress through thermal stress finite element method. The diffusion coefficient of boron in DAZ is as follows [15]:

$$
D=1.7 \times 10^{-9} \exp \left(-\frac{116 \mathrm{~kJ} \mathrm{~mol}^{-1}}{R T}\right)
$$

From Eq. (8), when temperature is $\mathrm{T}=1348 \mathrm{~K}$, The corresponding diffusion coefficient of boron is $5.439 \times 10^{-14} \mathrm{~m}^{2} \mathrm{~s}^{-1}$. The partial molar volume of boron is about $1.73 \times 10^{-6} \mathrm{~m}^{3} / \mathrm{mol}^{[16]}$. According to Eq. (4) and (7), the thermal conductivity and CET of DAZ are $2.04 \times 10^{-7} \mathrm{~W} /(\mathrm{m} \cdot \mathrm{K})$ and $0.577 \times 10^{-6} /{ }^{\circ} \mathrm{C}$, respectively.

The initial temperature boundary condition at the BNi-2/DAZ interface and the DAZ/BM interface are $T(y=0)=C(y=0)=3680$ and $T(y=a)=C(y=a)=0$, respectively. The equivalent temperature field is then introduced into the force analysis as a thermal load to obtain the diffusion stress.

\section{Result and analysis}

\section{Analysis of diffusion stress.}

In this paper, S11, S22 and S33 is the stress in the $x, y$, and $z$ axis direction. Due to the geometrical symmetry of the model, S11 is equal to S33; the $y$ direction can be regarded as free, which means that S22 is almost zero.
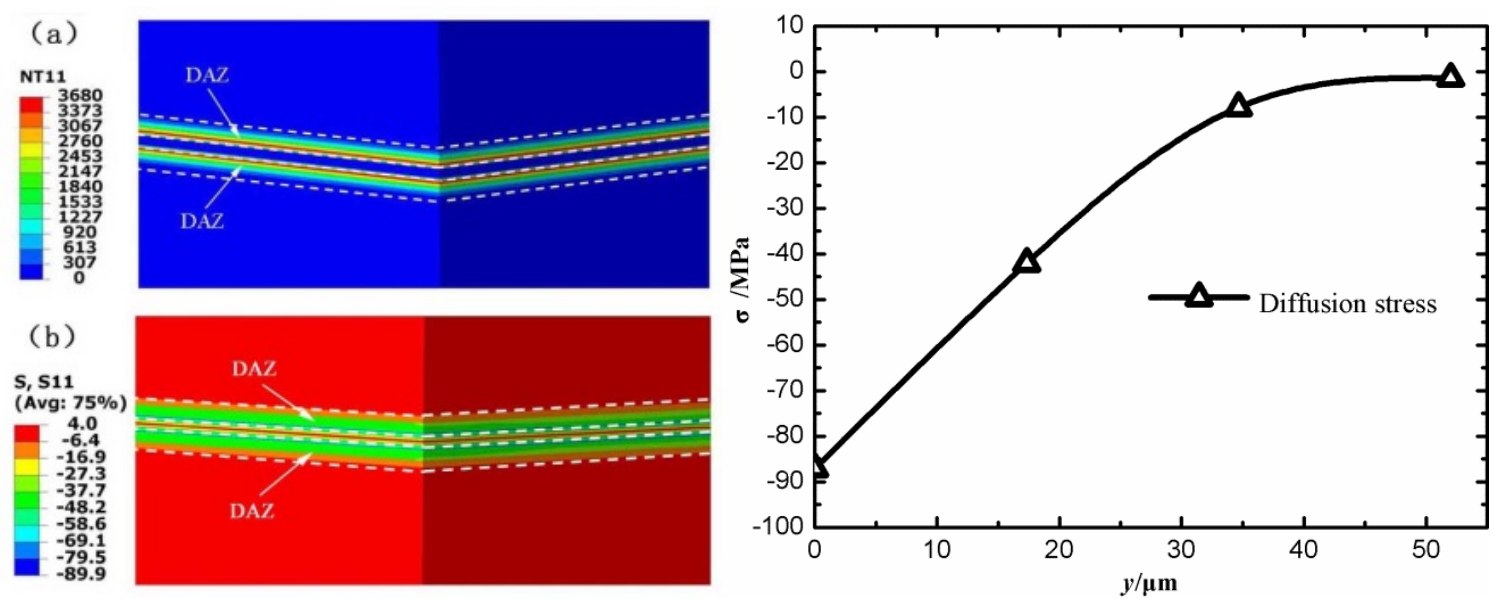

Fig. 4 Symmetry center position calculation result: Fig. 5 Stress Distribution in DAZ Layer

(a) Equivalent temperature field; (b) Diffusion stress

Fig. 4 (a) showed the diffusion of boron in the DAZ layer. After holding $45 \mathrm{~min}$, the boron in the DAZ layer diffused from the BNi-2/DAZ interface to the DAZ/BM interface, and the boron were unevenly distributed in the DAZ layer. As shown in Fig. 4 (b), the diffusion stress in the DAZ layer was compressive stress, and its maximum value was about $89.9 \mathrm{MPa}$ at the BNi-2/DAZ interface. The stress gradually decreases along the diffusion direction of boron, and it is close to zero at the DAZ/BM interface, as shown in Fig. 5. 
Analysis of stress after cooling.
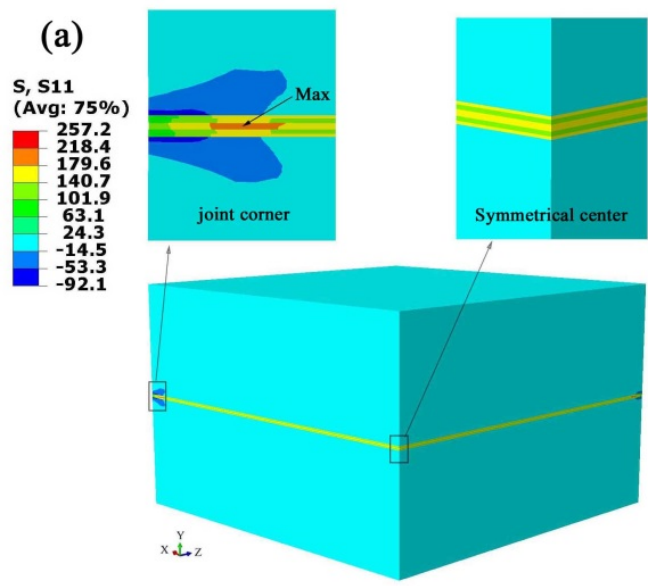

(b)

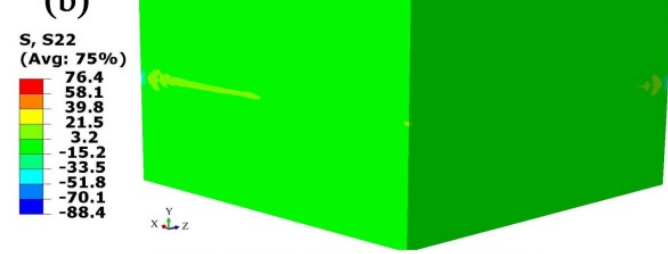

(c)
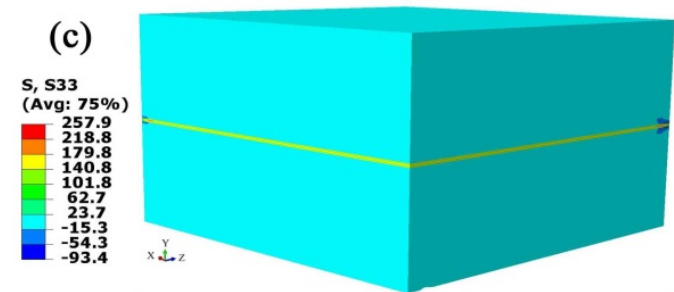

Fig. 6 Stress distribution of brazed joints: (a) S11; (b)S22; (c) S33

As can be seen from Fig. 6, the S11, S22 is higher in the BNi-2 layer than those of the base metal. The stress distribution along the brazing seam is symmetrical, especially the residual stress peak at the joint corner. The stress gradient in the matrix region is small and the stress level is close to zero. Due to the geometrical symmetry of the model, the stress S11 is the same as the S33, as shown in Fig. 6 (a) and (c), therefore S33 will be no longer considered in the subsequent discussion. In the model two paths denoted as P1 and P2 are taken for a detailed analysis, as shown in Fig. 3. Fig. 7 shows the distribution of stress along path P1 and P2, respectively. It can be seen that it is residual tensile stress in BNi-2 layer and DAZ layer, which is greater than those of other regions. Since the $y$ direction is almost unconstrained, the S22 is close to zero. From the BM to the BNi-2 layer, the stress increases rapidly to $+175 \mathrm{MPa}$; the stress in DAZ layer fluctuates at $+140 \mathrm{MPa}$. Therefore, the BNi-2 layer and DAZ layer need to be focused on. It is worth noting that the tensile stress in the vicinity of joint corner reaches its maximum value, which is the most vulnerable place to premature cracking.
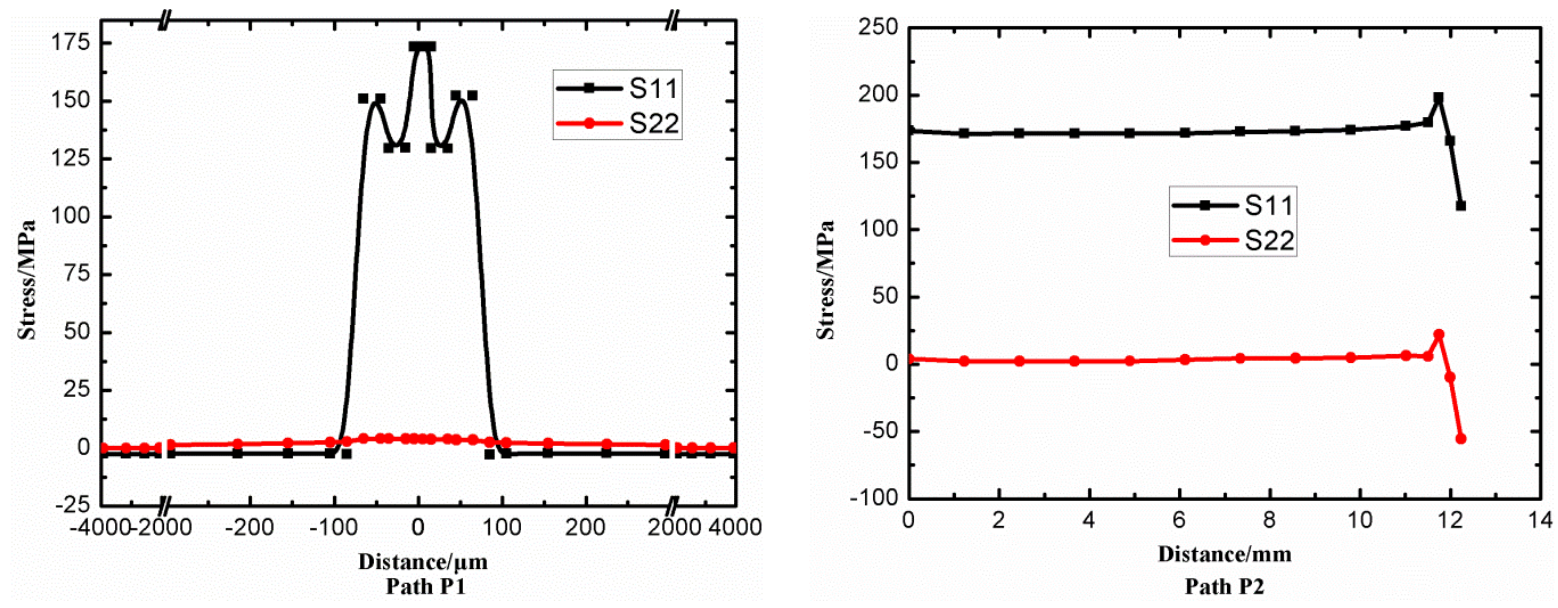

Fig. 7 Stress evolution along different reference paths

\section{Conclusion}

At the brazing temperature of $1075^{\circ} \mathrm{C}$ for $45 \mathrm{~min}$, the joint area can be divided into isothermal solidification layer (ISZ), diffusion affected layer (DAZ), and substrate (BM). The width of the DAZ layer is about $52 \mu \mathrm{m}$, and the thickness of the solder layer is about $40 \mu \mathrm{m}$.

In the incubation stage, the diffusion stress of the DAZ layer is compressive stress, and the maximum stress is at the BNi-2/DAZ interface, and the stress decreases gradually to zero along the boron diffusion direction. After the brazing joint is formed, both $\mathrm{BNi}-2$ and $\mathrm{DAZ}$ layers are identified as residual tensile stresses, and the tensile stress in the $\mathrm{BNi}-2$ layer reaches its maximum value in the vicinity of joint corner. The stress in the solder layer and the DAZ layer is greater than those of other regions, which needs paying attention to. 


\section{Acknowledgments}

This work was financially supported by Shanghai Pu Jiang Talent Project (14PJD015) fund.

\section{References}

[1] D. Aquaro and M. Pieve, High Temperature Compact Heat Exchangers: Performance of Advanced Metallic Recuperators for Power Plants,Proceedings of Fifth International Conference on Enhanced, Compactand Ultra-Compact Heat Exchangers: Science, Engineering andTechnology, Hoboken, NJ, USA, 2005, p 239-246

[2] Sun Jisheng, Liu Xiaofang. Study on Vacuum Brazing of Stainless Steel Radiator Core[J]. Materials Engineering, 1997(1):35-37.

[3] Chen H, Gong J M, Geng L Y. ASME PVP2006/ICPVT-11 Conference[J]. Vancouver, BC, Canada, 2006.

[4] Jiang W, Gong J, Tu S T, et al. Effect of geometric conditions on residual stress of brazed stainless steel plate-fin structure[J]. Nuclear Engineering and Design, 2008, 238(7): 1497-1502.

[5] Jiang W, Tu S T, Li G C, et al. Residual stress and plastic strain analysis in the brazed joint of bonded compliant seal design in planar solid oxide fuel cell[J]. Journal of Power Sources, 2010, 195(11): 3513-3522.

[6] Jiang W, Zhang Y, Woo W, et al. Three-dimensional simulation to study the influence of foil thickness on residual stress in the bonded compliant seal design of planar solid oxide fuel cell[J]. Journal of Power Sources, 2012, 209: 65-71.

[7] Chen Yongchong, Qi Lu, Zhang Yonggang, Chen Changlin. Phenomenological Theory of Solid Interdiffusion [J]. Journal of Peking University (Natural Science Edition).2006(02):168-174.

[8] Wang Yanfei, Gong Jianming, Rong Dongsong, Gao Feng. Measurement and Calculation of C Concentration and Diffusion Stress in Low Temperature Gas Carburizing of Stainless Steel[J]. Metallography.2004,50(4):409-414.

[9] Cheng Y T, Verbrugge M W. Evolution of stress within a spherical insertion electrode particle under potentiostatic and galvanostatic operation[J]. Journal of Power Sources, 2009, 190(2):453-460.

[10] An T, Qin F, Xia GF. Analytical Solutions and a Numerical Approach for Diffusion-Induced Stresses in Intermetallic Compound Layers of Solder Joints[J].Journal of Electronic Packaging. 2014, Vol.136(No.1): 011001

[11] Zhang Yucai. Creep Damage and Crack Propagation of Brazed Joints under Multi - axial Stress [D]. East China University of Science and Technology,2016.

[12] Ni Hongfang, Lin Xiang, Tu Shandong. Finite element simulation of three - dimensional residual stress field in multi - pass welding[J]. Mechanical strength,2004,26(2):218-222.

[13] Zhang Y C, Jiang W, Tu S T, et al. Using short-time creep relaxation effect to decrease the residual stress in the bonded compliant seal of planar solid oxide fuel cell-A finite element simulation[J]. Journal of Power Sources, 2014, 255:108-115.

[14] Guo C, Kelly P M. Boron solubility in Fe-Cr-B cast irons[J]. Materials Science and Engineering: A, 2003, 352(1): 0-45.

[15] I.Campos-Silva, M.Ortiz-Domínguez, O.Bravo-Bárcenas, M.A.Dou-Ruiz; D.Bravo- Bárcenas; C. Tapia-Quintero; M. Y. Jiménez-Reyes. Formation and kinetics of FeB/Fe2B layers and diffusion zone at the surface of AISI 316 borided steels[J]. Surface and Coatings Technology. 2010, Vol.205(No.2): 403-412.

[16] R. Ray, R. Hasegawa, C.-P. Chou and L. A. Davis. Iron-Boron Glassess: Density, Mechanical and Thermal behavor[J]. Scripta Metallurgica.1977, Vol.II: 973-978. 